\title{
Modulation of MAPK and NF-kB Signaling Pathways by Antioxidant Therapy in Skeletal Muscle of Heart Failure Rats
}

\author{
Paula F. Martinez ${ }^{\mathrm{a}, \mathrm{b}} \quad$ Camila Bonomo $^{\mathrm{a}}$ Daniele M. Guizoni ${ }^{\mathrm{a}}$ \\ Silvio A. Oliveira Junior ${ }^{a, b}$ Ricardo L. Damatto ${ }^{a}$ Marcelo D.M. Cezar \\ Aline R.R. Lima ${ }^{a}$ Luana U. Pagan ${ }^{a}$ Fabio R. Seiva ${ }^{c}$ Renata T. Bueno ${ }^{a}$ \\ Denise C. Fernandes $^{d}$ Francisco R. Laurindo ${ }^{d}$ Leonardo A.M. Zornoffa \\ Katashi Okoshia Marina P. Okoshi ${ }^{a}$
}

aBotucatu Medical School, UNESP, Botucatu, 'bederal University of Mato Grosso do Sul, Campo Grande, 'North of Parana State University, Bandeirantes, dHeart Institute (InCor)-HC-FMUSP, Vascular Biology Laboratory, Sao Paulo, Brazil

\section{Key Words}

Cardiac failure - Skeletal muscle - Myopathy - Oxidative stress - Intracellular signaling • Myocardial infarction

\begin{abstract}
Background/Aims: Although increased oxidative stress plays a role in heart failure (HF)-induced skeletal myopathy, signaling pathways involved in muscle changes and the role of antioxidant agents have been poorly addressed. We evaluated the effects of $N$-acetylcysteine (NAC) on intracellular signaling pathways potentially modulated by oxidative stress in soleus muscle from HF rats. Methods and Results: Four months after surgery, rats were assigned to Sham, myocardial infarction (MI)-C (without treatment), and MI-NAC (treated with $\mathrm{N}$-acetylcysteine) groups. Two months later, echocardiogram showed left ventricular dysfunction in MI-C; NAC attenuated diastolic dysfunction. Oxidative stress was evaluated in serum and soleus muscle; malondialdehyde was higher in MI-C than Sham and did not differ between MI-C and MINAC. Oxidized glutathione concentration in soleus muscle was similar in Sham and MI-C, and lower in MI-NAC than MI-C (Sham $0.168 \pm 0.056$; MI-C $0.223 \pm 0.073$; MI-NAC $0.136 \pm$ $0.023 \mathrm{nmol} / \mathrm{mg}$ tissue; $p=0.014)$. Western blot showed increased $\mathrm{p}$-JNK and decreased $\mathrm{p} 38$, ERK1/2, and $p$-ERK1/2 in infarcted rats. NAC restored ERK1/2. NF-KB p65 subunit was reduced; p-Ser276 in p65 and IkB was increased; and p-Ser536 unchanged in MI-C compared to Sham. NAC did not modify NF-KB p65 subunit, but decreased p-Ser276 and p-Ser536. Conclusion: $\mathrm{N}$-acetylcysteine modulates MAPK and NF-KB signaling pathways in soleus muscle of HF rats.
\end{abstract}




\section{Introduction}

Intrinsic skeletal muscle abnormalities have been described in chronic heart failure (HF) patients and hypothesized to play a role in exercise intolerance [1-3]. Skeletal muscle alterations such as atrophy, fibrosis, decreased oxidative capacity, altered myosin distribution, and contractile dysfunction have been well characterized in several experimental and clinical HF studies [4-11].

Systemic and myocardial oxidative stress is augmented during HF. More recently, increased oxidative stress was also observed in skeletal muscle [12-14]. However, the signaling pathways involved in oxidative stress-induced skeletal muscle changes during HF have been poorly addressed. Experimental studies suggest that mitogen-activated protein kinases (MAPK) and nuclear factor-kappaB (NF- $\mathrm{KB}$ ) signaling pathways may influence muscle response to oxidative stress in several conditions [15-17]. MAPK include four subfamilies, three of which have been well characterized: ERKs, JNKs, and p38-MAPK. When oxidative stress increases, MAPKs activation, specifically JNK and ERK, occurs after stimulation by kinases from the Src family [18]. MAPK can also be modulated by inflammatory cytokines, particularly TNF- $\alpha$, and are involved in the regulation of the myogenic regulatory factors myogenin, MyoD, and MRF4 [19, 20].

NF- $\kappa B$ activation depends on I $\kappa B$ phosphorylation, its endogenous inhibitor, by $I \kappa B$ kinases. This process leads to I $\kappa B$ ubiquitinization and subsequent proteasomal degradation, allowing NF- $\kappa \mathrm{B}$ heterodimer translocation to the nucleus, where NF- $\kappa \mathrm{B}$ activates specific target genes [21]. Recent studies showed that post-translational NF- $\kappa B$ changes, particularly phosphorylation and acetylation, may have a significant role in activating this transcriptional factor. Four different p65 NF- $\kappa B$ subunit serine residues can be phosphorylated, of which Ser276 can be phosphorylated by mitogen and stress-activated kinase-1 (MSK1) [22] and Ser536 by ribosomal protein S6 kinase-1 (RSK1) [23]. Since MAPKs activate both these kinases, they may represent an interaction point between MAPK and NF- $\kappa B$ signaling pathways. Although in some experimental conditions reactive oxygen species (ROS) can also

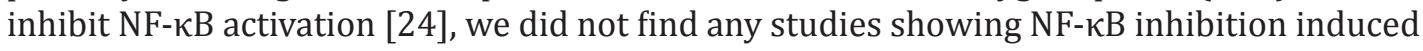
by increased oxidative stress in skeletal muscle. There is therefore, substantial evidence that MAPK and NF- $\mathrm{KB}$ are activated by oxidative stress. We did not identify any HF studies specifically analyzing the relationship between oxidative stress, myogenic regulatory factors, and MAPK and NF-KB signaling pathways in the slow-twitch soleus muscle.

Antioxidant therapy has been studied to prevent or treat cardiac changes during cardiac remodeling [25]. However, direct investigations on the role of anti-oxidants on heart failureinduced skeletal muscle abnormalities remain scarce [17]. Glutathione (L- $\gamma$ glutamylcysteinyl-glycine) is an endogenous tripeptide that plays a fundamental role in cellular defense against oxidative stress [26]. During HF, glutathione redox status is altered and its total concentration [27] decreased in cardiac tissue. $N$-acetylcysteine (NAC) is a molecule with antioxidant properties; it contains a sulfhydryl group and is a source of cysteine to glutathione synthesis. In a recent study, administration of NAC restored total glutathione levels and reduced oxidative stress markers in infarcted rat heart [27]. In this study, we evaluated the effects of NAC administration on intracellular signaling pathways modulated by oxidative stress in soleus muscle from heart failure rats.

\section{Material and Methods}

Experimental groups

Male Wistar rats $(200-250 \mathrm{~g})$ were housed in a room under controlled temperature and light-dark cycle. Food and water were supplied ad libitum. All experiments were approved by the Ethics Committee of Botucatu Medical School, Universidade Estadual Paulista, UNESP (protocol number 961-2012), and have therefore been performed in accordance with the ethical standards laid down in the 1964 Declaration of Helsinki and its later amendments. 
Myocardial infarction (MI) was induced by ligating the anterior descending coronary artery [28]. Four months later, rats were assigned to three groups: Sham, MI-C (MI without treatment), and MI-NAC (MI treated with $\mathrm{N}$-acetylcysteine, $120 \mathrm{mg} / \mathrm{kg}$ /day). Six months after surgery, rats were euthanized. At euthanasia, two observers determined whether the clinical and pathologic HF features were present or absent. Tachypnea/ labored respiration was the clinical finding. Pathologic findings included pleuropericardial effusion, left atrial thrombi, pulmonary congestion (lung weight-to-body weight ratio $>2$ standard deviation above sham group mean), and right ventricular hypertrophy (right ventricle weight-to- body weight ratio $>0.8 \mathrm{mg} / \mathrm{g}$ ) [29-31].

\section{Echocardiographic evaluation}

Echocardiogram was performed before and after NAC treatment (Vivid S6, General Electric Medical Systems, Tirat Carmel, Israel) using a 5 to $11.5 \mathrm{MHz}$ multifrequency probe, according to a previously described method [32-34].

Rats were anesthetized by intramuscular injection of a mixture of ketamine $(50 \mathrm{mg} / \mathrm{kg})$ and xylazine $(0.5 \mathrm{mg} / \mathrm{kg})$. A two-dimensional parasternal short-axis view of the left ventricle (LV) was obtained at the level of the papillary muscles. M-mode tracings were obtained from short-axis views of the LV at or just below the tip of the mitral-valve leaflets, and at the level of the aortic valve and left atrium. M-mode images of the LV were printed on a black-and-white thermal printer (Sony UP-890MD). All cardiac structures were manually measured by the same observer (K.O.) according to the leading-edge method of the American Society of Echocardiography [35]. The measurements obtained were the mean of at least five cardiac cycles on the M-mode tracings. The following structural variables were measured: left atrium (LA) diameter, LV diastolic and systolic dimensions (LVDD and LVSD, respectively), LV diastolic posterior wall thickness (PWT), and aortic diameter (AO). Left ventricular function was assessed by the following parameters: endocardial fractional shortening (FS), fractional area change (FAC), posterior wall shortening velocity (PWSV), earlyto-late diastolic mitral inflow velocities (E/A) ratio, E-wave deceleration time (EDT), and isovolumetric relaxation time (IVRT).

\section{Infarct size}

Left ventricle (LV) samples were fixed in a 10\% buffered formalin solution for $48 \mathrm{~h}$ and stained with haematoxylin and eosin. Infarction size was calculated by dividing the sum of endocardial and epicardial infarcted ventricular lengths by the sum of total (infarcted and viable myocardial) endocardial and epicardial ventricular circumferences. The measurements were acquired from midventricular slices (5-6 mm from the apex) and analysed in a microscope (Leica DM LS; Nussloch, Germany) attached to a computerized imaging analysis system (Media Cybernetics, Silver Spring, MD, USA) [28]. Rats with small MI size $(<30 \%)$ were excluded from this study.

\section{Skeletal muscle morphology}

Serial transverse sections of the soleus muscles mid belly were cut at $10 \mu \mathrm{m}$ thicknesses in a cryostat cooled to $-20^{\circ} \mathrm{C}$. The general morphology and cross-sectional fiber areas were evaluated in sections stained with haematoxylin and eosin. At least 200 cross-sectional fiber areas were measured from each soleus muscle. The measurements were performed using a compound microscope (Leica DM LS; Nussloch, Germany) attached to a computerized imaging analysis system (Media Cybernetics, Silver Spring, MD, USA) [36].

Myosin heavy chain (MyHC) isoforms

MyHC isoform analysis was performed in duplicate by sodium dodecyl sulphate polyacrylamide gel electrophoresis (SDS-PAGE) [36]. Frozen samples of soleus muscle were homogenized in $0.8 \mathrm{~mL}$ of solution containing $50 \mathrm{mM}$ phosphate potassium buffer ( $\mathrm{pH} 7.0$ ), $0.3 \mathrm{M}$ sucrose, $0.5 \mathrm{mM}$ dithiotreitol (DTT), $1 \mathrm{mM}$ ethylenediaminetetracetic acid (EDTA), $0.3 \mathrm{mM}$ phenylmetylsulphonyl fluoride, $10 \mathrm{mM}$ sodium fluoride, and protease inhibitor cocktail (Sigma, St. Louis, MO, USA). Homogenates were centrifuged at $12,000 \mathrm{~g}$ at $4^{\circ} \mathrm{C}$ for $20 \mathrm{~min}$ to remove insoluble tissue. After quantification of total protein in the supernatant, samples were diluted to a final concentration of $1 \mu \mathrm{g}$ of protein/ $\mu \mathrm{L}$ in a solution containing $65 \%$ (vol/vol) glycerol, $2.5 \%$ (vol/vol) 2-mercaptoethanol, 1.15\% (wt/vol) SDS, and $0.45 \%$ (wt/vol) Tris- $\mathrm{HCl}$ (pH 6.8). Twelve $\mu \mathrm{L}$ of the diluted extracts were loaded onto a $7-10 \%$ SDS-PAGE separating gel with a $4 \%$ stacking gel, run overnight 


\section{Cellular Physiology Cell Physiol Biochem 2016;39:371-384

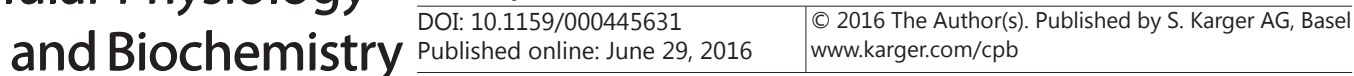

Martinez et al.: Oxidative Stress and Intracellular Signaling in Heart Failure-Induced Myopathy

at $70 \mathrm{~V}$, and stained with Coomassie blue. Two MyHC isoforms, MyHC I and MyHC IIa, were identified according to molecular mass and quantified by densitometry. Their relative amounts were expressed as the percentage of total myosin heavy chain amount.

\section{Metabolic enzymes activity}

Soleus muscle samples ( $200 \mathrm{mg}$ ) were homogenized in $5 \mathrm{~mL}$ of a cold $0.1 \mathrm{M}$ phosphate buffer, $\mathrm{pH}$ 7.4. Tissue was homogenized and centrifuged $(10,000 \times \mathrm{g})$ for $15 \mathrm{~min}$; the supernatant was assayed for total protein, $\beta$-hydroxyacyl coenzyme-A dehydrogenase (OHADH, E.C.1.1.1.35.), and citrate synthase (CS, E.C.4.1.3.7.) activities by spectrophotometry, as previously described [37].

\section{Malondialdehyde serum concentration}

Lipid peroxidation was assessed by measuring malondialdehyde (MDA) by high performance liquid chromatography (HPLC), as reported previously [38]. MDA was quantified by comparison of integrated peak areas between samples and standard solution under identical chromatographic conditions.

\section{3-Nitrotyrosine serum concentration}

Nitrotyrosine concentration was measured by enzyme-linked immunosorbent assay (ELISA) using OxiSelect ${ }^{T M}$ Nitrotyrosine ELISA Kit (STA-305, Cell Biolabs, San Diego, CA, USA).

\section{Circulating TNF- $\alpha$}

TNF- $\alpha$ serum concentration was measured by ELISA using a rat TNF- $\alpha$ kit (\#KCR3011, Invitrogen, Camarillo, CA, USA).

\section{Real-time quantitative reverse transcription-polymerase chain reaction (RT-PCR)}

Soleus muscle total RNA was extracted with TRIzol reagent. cDNA was submitted to real time PCR using a customized assay containing sense and antisense primers and a Taqman probe (Applied Biosystems, Foster City, CA, USA) specific to each gene: myogenin (Taqman assay Rn00567418_m1), MyoD (Rn00598571_m1), and MRF4 (Rn00565920_m1) [39, 40]. Expression data were normalized to reference gene expressions: cyclophilin (Rn00690933_m1), and GAPDH (Rn01775763_g1).

\section{Western blot}

Protein levels were analyzed using specific antibodies (Santa Cruz Biotechnology Inc., CA, USA): MyoD (sc-760), myogenin (sc-576), MRF4 (sc-301), p-JNK (sc-6254), total JNK1/2 (sc-137019), p-ERK1/2 (sc16982), total ERK 1 (sc-93), p-p38-MAPK (sc-17852), total p38-MAPK (sc-7972), p-IкB- $\alpha$ (sc-101713),

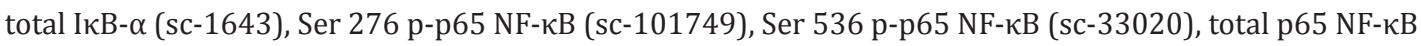
(sc-7151), p-Src (sc-101802), total Src (sc-5266), p-MSK1 (sc-130205), and total MSK1 (sc-25417). Protein levels were normalized to those of GAPDH (6C5-sc-32233) [41, 42].

Briefly, soleus muscle tendons were discarded and only the muscle belly was used for protein analysis. Muscle protein was extracted using RIPA buffer (containing proteases and phosphatases inhibitors) and the protein content of supernatant was quantified by the Bradford's method. Samples were separated on a polyacrylamide gel and then transferred to a nitrocellulose membrane. After blockage, membrane was incubated with the primary antibodies. Membrane was washed with TBS and Tween 20 and incubated with secondary peroxidase-conjugated antibodies. Super Signal ${ }^{\circledR}$ West Pico Chemiluminescent Substrate (Pierce Protein Research Products, Rockford, USA) was used to detect bound antibodies.

Glutathione concentration and redox status in soleus muscle

Soleus muscle fragments (30 - $40 \mathrm{mg}$ ) were homogenized in $100 \mathrm{mM}$ phosphate buffer (pH 7.0; 250 $\mu \mathrm{L} / 10 \mathrm{mg}$ tissue), and centrifuged at $12000 \mathrm{~g}$ for $10 \mathrm{~min}$ at $4^{\circ} \mathrm{C}$. A sample of the supernatant $(200 \mu \mathrm{L}) \mathrm{was}$ transferred to another tube and $5 \%$ sulphosalicylic acid $(200 \mu \mathrm{L})$ was added to precipitate proteins. Then, Glutathione Fluorescent Detection Kit (Arbor Assays) was added to quantify glutathione total concentration and redox status. The kit utilizes a non-fluorescent molecule, ThioStar ${ }^{\circledR}$, which covalently binds to the free thiol group of glutathione and yields a highly fluorescent product. After mixing the samples with ThioStar ${ }^{\circledR}$ and incubating for $15 \mathrm{~min}$ at room temperature, the fluorescent product was read (excitation $390 \mathrm{~nm}$, emission $510 \mathrm{~nm}$ ) in a spectrofluorometer (Spectramax 340, Molecular Devices) and reduced (or free) 
Martinez et al.: Oxidative Stress and Intracellular Signaling in Heart Failure-Induced Myopathy

glutathione (GSH) concentration was measured. Subsequently, a reaction mixture was added to convert all the oxidized glutathione (GSSG) into free GSH, which then reacted with the excess of ThioStar ${ }^{\circledast}$ to yield the signal related to total glutathione content. A standard curve was used to calculate total and reduced glutathione concentrations. Oxidized glutathione concentration was obtained by the following calculation: GSSG $=($ Total GSH - reduced GSH) $/ 2$. Results were normalized to the muscle fragment weight.

\section{Statistical analysis}

Data are expressed as mean \pm standard deviation. Comparisons between groups were performed by one-way ANOVA and Bonferroni post hoc test (interest comparisons: Sham versus MI-C and MI-C versus MINAC). The Student's $t$-test was used to compare MI size. Frequency of heart failure features was assessed by the Goodman test. Significance level was set at 5\%.

\section{Results}

\section{Experimental groups and anatomical variables}

Sham group rats $(\mathrm{n}=24)$ did not present any HF features. The frequency of HF features did not differ between MI-NAC and MI-C groups (Table 1). Anatomical data are presented in Table 2. Soleus muscle weight (Sham $0.24 \pm 0.03$; MI-C $0.24 \pm 0.04$; MI-NAC $0.23 \pm 0.03 \mathrm{~g}$ ) and soleus weight-to-body weight ratio (Sham $0.48 \pm 0.07$; MI-C $0.49 \pm 0.05$; MI-NAC $0.47 \pm$ $0.07 \mathrm{mg} / \mathrm{kg}$ ) did not differ between groups. The lack of skeletal muscle atrophy suggests that we have evaluated our rats before the heart failure-induced catabolic state was completely activated. MI size did not differ between MI-C (47.6 $\pm 5.9 \%)$ and MI-NAC (47.7 $\pm 8.3 \%)$ groups.

Table 1. Frequency of heart failure features in the infarcted rats

\begin{tabular}{lcc}
\hline & \multicolumn{2}{c}{ Frequency (\%) } \\
& MI-C & MI-NAC \\
$(\mathrm{n}=24)$ \\
\hline Tachypnea/labored respiration & 54.2 & 41.7 \\
Left atrial thrombi & 8.3 & 20.8 \\
Pleuropericardial effusion & 79.2 & 66.7 \\
Pulmonary congestion & 75.0 & 58.3 \\
Right ventricular hypertrophy & 75.0 & 66.7 \\
\hline MI-C: infarcted rats without treatment; MI-NAC: infarcted rats treated with $N$-acetylcysteine. Goodman test; $p>0.05$ \\
\hline
\end{tabular}

Table 2. Anatomical data

\begin{tabular}{lccc}
\hline & $\begin{array}{c}\text { Sham } \\
(\mathrm{n}=24)\end{array}$ & $\begin{array}{c}\text { MI-C } \\
(\mathrm{n}=24)\end{array}$ & $\begin{array}{c}\text { MI-NAC } \\
(\mathrm{n}=24)\end{array}$ \\
\hline BW $(\mathrm{g})$ & $502 \pm 47$ & $487 \pm 71$ & $482 \pm 55$ \\
LVW $(\mathrm{g})$ & $0.90 \pm 0.09$ & $0.94 \pm 0.13$ & $0.95 \pm 0.12$ \\
RVW $(\mathrm{g})$ & $0.27 \pm 0.03$ & $0.49 \pm 0.15^{*}$ & $0.45 \pm 0.16$ \\
Lungs (g) & $2.08 \pm 0.27$ & $3.13 \pm 0.86^{*}$ & $2.85 \pm 0.70$ \\
LVW/BW (mg/g) & $1.88 \pm 0.13$ & $1.93 \pm 0.16^{*}$ & $1.97 \pm 0.19$ \\
RVW/BW (mg/g) & $0.54 \pm 0.06$ & $1.00 \pm 0.28^{*}$ & $0.94 \pm 0.31$ \\
Lungs/BW (mg/g) & $4.17 \pm 0.53$ & $6.44 \pm 1.61^{*}$ & $5.97 \pm 1.53$ \\
\hline
\end{tabular}

MI-C: infarcted rats without treatment; MI-NAC: infarcted rats treated with $N$-acetylcysteine; BW: body weight; LVW: left ventricle weight; RVW: right ventricular weight. Data are expressed as the mean \pm standard deviation. ${ }^{*} p<0.05$ vs. sham; ANOVA and Bonferroni 
Martinez et al.: Oxidative Stress and Intracellular Signaling in Heart Failure-Induced Myopathy

Table 3. Cardiac structure parameters

\begin{tabular}{lccc}
\hline & $\begin{array}{c}\text { Sham } \\
(\mathrm{n}=24)\end{array}$ & $\begin{array}{c}\text { MI-C } \\
(\mathrm{n}=24)\end{array}$ & $\begin{array}{c}\text { MI-NAC } \\
(\mathrm{n}=24)\end{array}$ \\
\hline LVDD $(\mathrm{mm})$ & $8.83 \pm 0.51$ & $11.32 \pm 1.39^{*}$ & $10.86 \pm 0.93$ \\
LVDD $/$ BW $(\mathrm{mm} / \mathrm{kg})$ & $17.05 \pm 1.53$ & $22.62 \pm 2.75^{*}$ & $21.88 \pm 2.18$ \\
LVSD $(\mathrm{mm})$ & $4.43 \pm 0.63$ & $9.06 \pm 1.45^{*}$ & $8.73 \pm 1.23$ \\
PWT (mm) & $1.51 \pm 0.12$ & $1.85 \pm 0.30^{*}$ & $1.76 \pm 0.35$ \\
AO (mm) & $4.0 \pm 0.2$ & $3.7 \pm 0.2^{*}$ & $3.8 \pm 0.2$ \\
LA (mm) & $6.1 \pm 0.5$ & $8.5 \pm 1.0^{*}$ & $8.3 \pm 1.2$ \\
LA/BW $(\mathrm{mm} / \mathrm{kg})$ & $11.68 \pm 1.31$ & $17.08 \pm 2.11^{*}$ & $16.81 \pm 2.57$ \\
\hline
\end{tabular}

MI-C: infarcted rats without treatment; MI-NAC: infarcted rats treated with $N$-acetylcysteine. LVDD and LVSD: LV diastolic and systolic diameters, respectively; BW: body weight; PWT: LV diastolic posterior wall thickness; AO: aorta diameter; LA: left atrium diameter. Data are expressed as the mean \pm standard deviation. ${ }^{*} p<0.05$ vs. sham; ANOVA and Bonferroni

Table 4. Left ventricular function data

\begin{tabular}{lccc}
\hline & $\begin{array}{c}\text { Sham } \\
(\mathrm{n}=24)\end{array}$ & $\begin{array}{c}\text { MI-C } \\
(\mathrm{n}=24)\end{array}$ & $\begin{array}{c}\text { MI-NAC } \\
(\mathrm{n}=24)\end{array}$ \\
\hline HR (beats/min) & $281 \pm 41$ & $285 \pm 56$ & $265 \pm 34$ \\
FS (\%) & $49.9 \pm 5.6$ & $20.3 \pm 4.6^{*}$ & $19.9 \pm 5.6$ \\
FAC (\%) & $67.5 \pm 5.5$ & $24.9 \pm 5.9^{*}$ & $25.0 \pm 5.9$ \\
PWSV (mm/s) & $36.9 \pm 3.1$ & $21.6 \pm 3.9^{*}$ & $21.3 \pm 4.7$ \\
E/A & $1.44 \pm 0.17$ & $5.21 \pm 2.44^{*}$ & $3.91 \pm 2.13 \#$ \\
EDT (ms) & $48.9 \pm 6.0$ & $36.5 \pm 8.8^{*}$ & $39.9 \pm 10.2$ \\
IVRT (ms) & $27.0 \pm 4.3$ & $32.8 \pm 7.0^{*}$ & $32.6 \pm 7.5$ \\
\hline
\end{tabular}

MI-C: infarcted rats without treatment; MI-NAC: infarcted rats treated with $N$-acetylcysteine. HR: heart rate; FS: endocardial fractional shortening; FAC: fractional area change; shortening; PWSV: posterior wall shortening velocity; E/A: early-to-late diastolic mitral inflow ratio; EDT: E-wave deceleration time; IVRT: isovolumetric relaxation time. Data are expressed as the mean \pm standard deviation. ${ }^{*} p<0.05$ vs. sham; $\# p<0.05$ vs. MI-C; ANOVA and Bonferroni

\section{Echocardiograph evaluation}

Before NAC administration, all echocardiographic variables were similar between MI-C and MI-NAC groups (data not shown). Cardiac structural and LV function variables evaluated at the end of the experiment are shown in Tables 3 and 4, respectively.

\section{Skeletal myopathy characterization}

Fiber cross sectional areas did not differ between groups (Sham 3,408 \pm 381 ; MI-C $3,775 \pm 490 ;$ MI-NAC $3,784 \pm 513 \mu \mathrm{m}^{2} ; p>0.05$ ). Representative histological sections of haematoxylin and eosin-stained soleus muscle are presented in Fig. 1.

$\beta$-hydroxyacyl coenzyme-A dehydrogenase activity was lower in MI-C than Sham and similar in MI-C and MI-NAC (Sham 73.6 \pm 9.8; MI-C $61.0 \pm 7.0$; MI-NAC $59.5 \pm 5.1 \mathrm{nmol} / \mathrm{mg}$ protein; $p=0.002)$. Citrate synthase activity tended ( $p=0.081)$ to be lower in MI-C than Sham, and was lower ( $p=0.003$ ) in MI-NAC than MI-C (Sham $168 \pm 23$; MI-C $148 \pm 16$; MINAC $115 \pm 15 \mathrm{nmol} / \mathrm{mg}$ protein; $p<0.001)$.

The percentage of myosin heavy chain IIa isoform was lower in MI-C than Sham, and higher in MI-NAC than MI-C (Sham 22.2 \pm 4.46; MI-C 15.9 \pm 3.56 ; MI-NAC $20.6 \pm 3.26 \%$; $p=$ 0.009). Myosin heavy chain representative bands are shown in Fig. 2.

\section{Systemic oxidative stress}

MDA serum concentration was higher in MI-C compared to Sham and did not differ between MI-C and MI-NAC (Sham $0.98 \pm 0.07$; MI-C $1.22 \pm 0.10$; MI-NAC $1.37 \pm 0.16 \mu \mathrm{mol}$ / $\mathrm{mL} ; p<0.001$ ), showing that both infarcted groups presented increased systemic lipid peroxidation. However, as serum concentration of 3-nitrotyrosine was similar in Sham and 


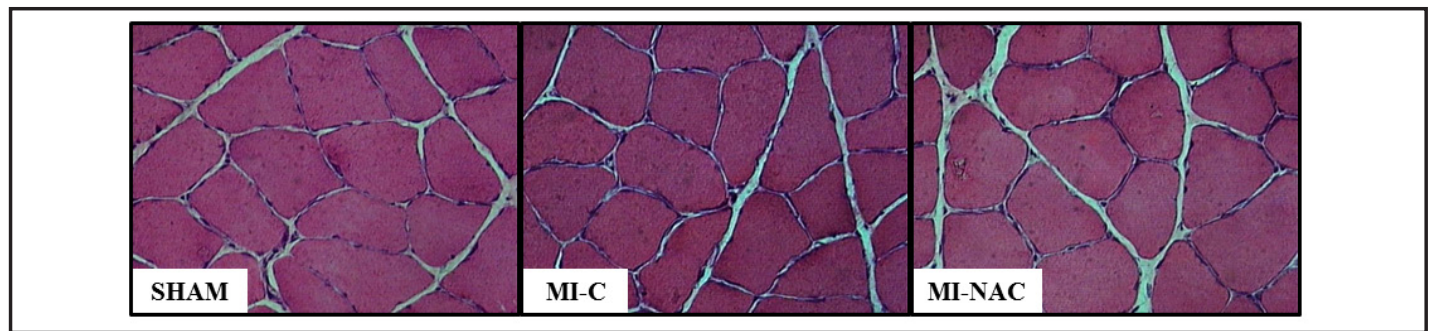

Fig. 1. Representative histological sections (400-fold magnification) of haematoxylin and eosin-stained soleus muscle from Sham, infarcted rats without treatment (MI-C), and infarcted rats treated with N-acetylcysteine (MI-NAC).

Fig. 2. Representative bands of myosin heavy chain isoforms (MyHC I and MyHC IIa) and percentage of MyHC IIa in soleus muscle. Sham ( $\mathrm{n}=8)$; infarcted rats without treatment MI-C; $\mathrm{n}=8$ ); infarcted rats treated with $\mathrm{N}$-acetylcysteine (MI-NAC; $\mathrm{n}=8$ ). Data are expressed as the mean \pm standard deviation; * $p<0.05$ vs Sham; \# $p<0.05$ vs MI-C; ANOVA and Bonferroni.

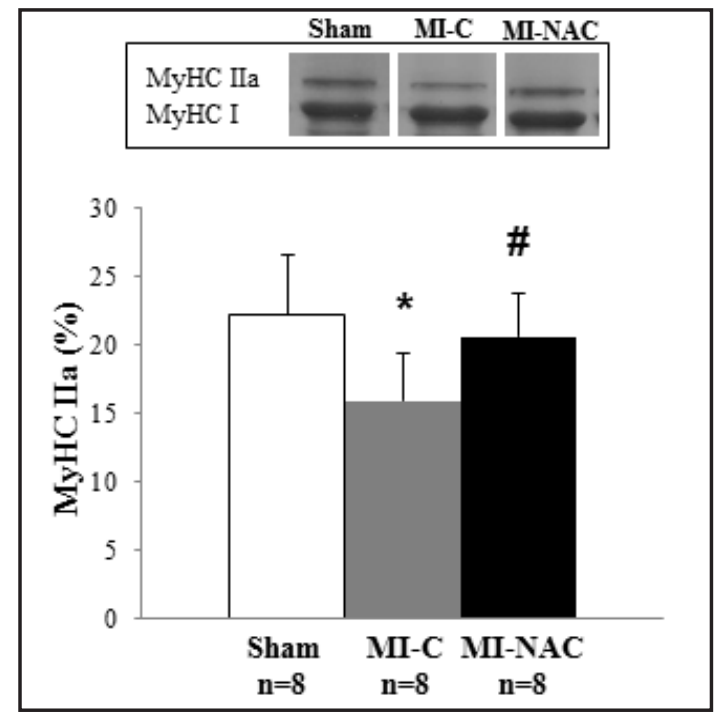

MI-C, and lower in MI-NAC than MI-C (Sham $126 \pm 50$; MI-C $176 \pm 50$; MI-NAC $98 \pm 48$ nM; $p$ $=0.032$ ), we can conclude that systemic oxidative stress was attenuated by NAC.

Glutathione concentration and redox status in soleus muscle

Total (Sham $2.89 \pm 0.41$; MI-C $2.93 \pm 0.44$; MI-NAC $2.51 \pm 0.51 \mathrm{nmol} / \mathrm{mg}$ tissue; $p=$ 0.125 ) and reduced (Sham 2.42 \pm 0.48 ; MI-C $2.52 \pm 0.29$; MI-NAC $2.22 \pm 0.52 \mathrm{nmol} / \mathrm{mg}$ tissue; $p=0.403$ ) glutathione concentrations did not differ between groups. Oxidized glutathione concentration was similar in Sham and MI-C, and lower in MI-NAC than MI-C (Sham $0.168 \pm$ 0.056 ; MI-C $0.223 \pm 0.073$; MI-NAC $0.136 \pm 0.023 \mathrm{nmol} / \mathrm{mg}$ tissue; $p=0.014$ ).

Circulating TNF- $\alpha$ levels

TNF- $\alpha$ serum concentration was higher in MI-C than Sham and similar in MI-NAC and MI-C (Sham $9.41 \pm 0.50$; MI-C $11.16 \pm 1.98$; MI-NAC $10.29 \pm 2.04 \mathrm{pg} / \mathrm{mL} ; p=0.039$ ).

\section{Gene expression}

MyoD (Sham $1.00 \pm 0.38$; MI-C $0.78 \pm 0.33$; MI-NAC $0.77 \pm 0.26$ arbitrary units; $p>0.05$ ) and myogenin (Sham $1.00 \pm 0.25$; MI-C $0.91 \pm 0.15$; MI-NAC $0.98 \pm 0.17$ arbitrary units; $p>$ $0.05)$ gene expression was similar in all groups. MRF4 expression was similar in Sham and MI-C, and greater in MI-NAC than MI-C (Sham $1.00 \pm 0.25$; MI-C $1.00 \pm 0.16$; MI-NAC $1.33 \pm$ 0.27 arbitrary units; $p=0.01$ ).

Protein levels

MAPK proteins expression is shown in Fig. 3. Phosphorylated ERK (p-ERK) was lower in MI-C than in Sham (Sham $1.00 \pm 0.32$; MI-C $0.57 \pm 0.11$; MI-NAC $0.82 \pm 0.35$ arbitrary units; $p=0.021$ ). Total ERK was lower in MI-C than Sham and higher in MI-NAC than in MI-C (Sham 
Fig. 3. Protein levels and representative Western blots of mitogen-activated protein kinases (MAPK) in soleus muscle. A: Phosphorilated and total ERK; B: Phosphorilated and total JNK, and C: Phosphorilated and total p38MAPK. Sham $(\mathrm{n}=8)$; infarcted rats without treatment (MI-C; $\mathrm{n}=8$ ); infarcted rats treated with $\mathrm{N}$-acetylcysteine (MINAC; $\mathrm{n}=8$ ). Data are expressed as the mean \pm standard deviation; ${ }^{*}$ $p<0.05$ vs Sham; \# $p$ $<0.05$ vs MI-C; ANOVA and Bonferroni.

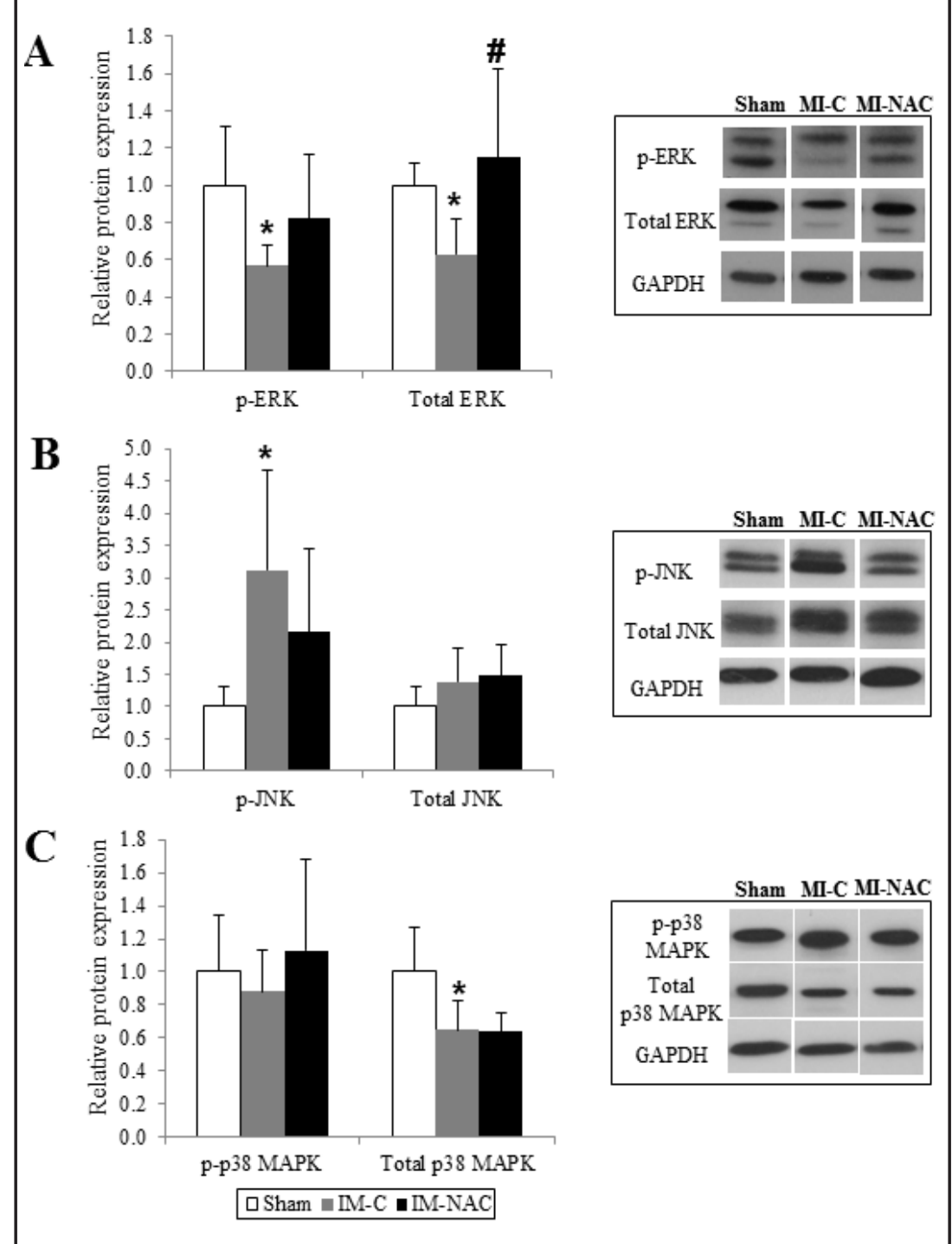

$1.00 \pm 0.12$; MI-C $0.63 \pm 0.19 ;$ MI-NAC $1.15 \pm 0.47$ arbitrary units; $p=0.006$ ). Phosphorylated JNK (p-JNK) expression was higher in MI-C than Sham (Sham 1.00 \pm 0.31; MI-C $3.12 \pm 1.54$; MI-NAC $2.15 \pm 1.31$ arbitrary units; $p=0.007$ ). Total JNK (Sham $1.00 \pm 0.32$; MI-C $1.38 \pm 0.52$; MI-NAC $1.48 \pm 0.47$ arbitrary units; $p=0.447$ ) and phosphorylated p38 MAPK (p-p38 MAPK: Sham $1.00 \pm 0.34$; MI-C $0.88 \pm 0.25$; MI-NAC $1.13 \pm 0.55$ arbitrary units; $p=0.478$ ) did not differ between groups. Total p38 MAPK was lower in MI-C than in Sham (Sham $1.00 \pm 0.27$; MI-C $0.65 \pm 0.18$; MI-NAC $0.64 \pm 0.11$ arbitrary units; $p=0.002$ ).

We next showed that $N$-acetylcysteine reduced phosphorylation of NF-кB (Fig. 4). Serine 276-phosphorylated NF- $\kappa B$ (Ser 276 NF- $\kappa B$ ) was higher in MI-C than in Sham and lower in MI-NAC than in MI-C (Sham $1.00 \pm 0.45$; MI-C $1.40 \pm 0.25$; MI-NAC $0.95 \pm 0.25$ arbitrary units;

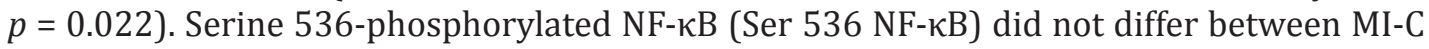
and Sham and was lower in MI-NAC than in MI-C (Sham 1.00 \pm 0.16 ; MI-C $0.85 \pm 0.11$; MI-NAC $0.46 \pm 0.17$ arbitrary units; $p<0.001$ ). Total NF- $\mathrm{KB}$ was lower in MI-C than in Sham (Sham $1.00 \pm 0.25$; MI-C $0.73 \pm 0.10$; MI-NAC $0.68 \pm 0.18$ arbitrary units; $p=0.005$ ). These in vivo results are in accordance with data from cell culture showing that under TNF- $\alpha$ stimulation, antioxidant intervention did not prevent JNK activation, but reduced p65-Ser276 residue phosphorylation and expression of TNF- $\alpha$-inducible NF-kB-dependent genes [43].

MAPK and NF- $\kappa B$ signaling pathways-related proteins expression is shown in Fig. 5.

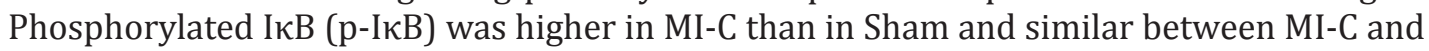




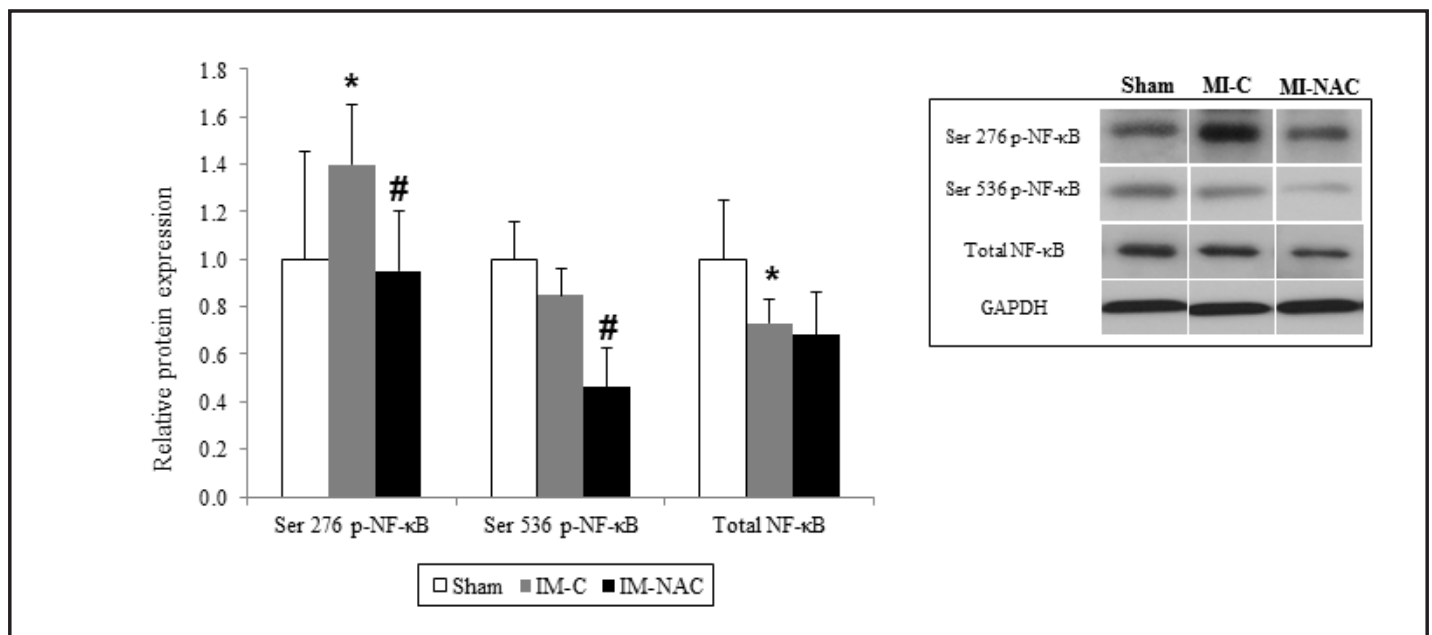

Fig. 4. Protein levels and representative Western blots of nuclear factor-kappaB (NF- $\kappa$ B) p65 subunit (Ser276 and Ser 536 phosphorylated and total forms) in soleus muscle. Sham ( $\mathrm{n}=8$ ); infarcted rats without treatment (MI-C; $\mathrm{n}=8$ ); infarcted rats treated with $\mathrm{N}$-acetylcysteine (MI-NAC; $\mathrm{n}=8$ ). Data are expressed as the mean \pm standard deviation; ${ }^{*} p<0.05$ vs Sham; \# $p<0.05$ vs MI-C; ANOVA and Bonferroni.

Fig. 5. Protein levels and representative Western blots of phosphorylated (p-IкB) and total IкB (A) and Src (B) in soleus muscle. Sham; infarcted rats without treatment (MI-C; $\mathrm{n}=8$ ); infarcted rats treated with $N$-acetylcysteine (MI-NAC; $\mathrm{n}=8$ ). Data are expressed as the mean \pm standard deviation; ${ }^{*} p<0.05$ vs Sham; \# $p<0.05$ vs MI-C; ANOVA and Bonferroni.
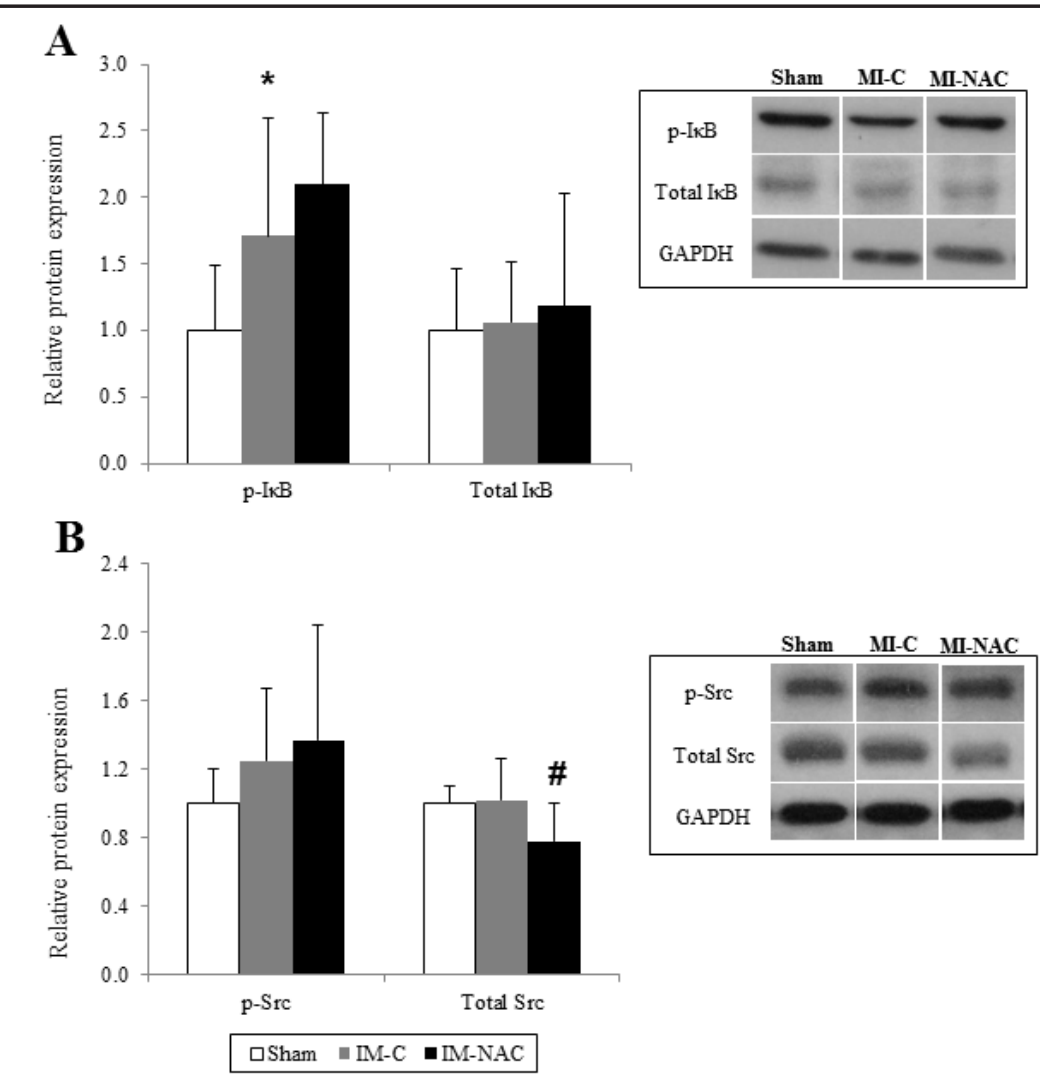

MI-NAC (Sham $1.00 \pm 0.49$; MI-C $1.71 \pm 0.89$; MI-NAC $2.10 \pm 0.54$ arbitrary units; $\mathrm{p}=0.01$ ). Total IкB did not differ between groups. Phosphorylated Src (p-Src) and MSK1 (p-MSK1: Sham $1.00 \pm 0.37$; MI-C $1.08 \pm 0.40$; MI-NAC $0.97 \pm 0.61$ arbitrary units) did not differ between groups. Total Src did not differ between Sham and MI-C groups, but was lower in MI-NAC than in MI-C. (Sham $1.00 \pm 0.10$; MI-C $1.02 \pm 0.24$; MI-NAC $0.78 \pm 0.22$ arbitrary units; $\mathrm{p}=0.04)$. Total MSK1 was lower in MI-C than in Sham $(p<0.05)$ and did not differ 
between MI-C and MI-NAC (Sham $1.00 \pm 0.26$; MI-C $0.53 \pm 0.14$; MI-NAC $0.43 \pm 0.09$ arbitrary units).

Protein levels of myogenic regulatory factors were similar in all groups for MyoD (Sham $1.00 \pm 0.38$; MI-C $0.70 \pm 0.38$; MI-NAC $0.75 \pm 0.33$ arbitrary units; $p>0.05$ ), myogenin (Sham $1.00 \pm 0.21$; MI-C $1.55 \pm 0.59$; MI-NAC $2.12 \pm 1.44$ arbitrary units; $p>0.05$ ), and MRF4 (Sham $1.00 \pm 0.10$; MI-C $0.86 \pm 0.39$; MI-NAC $1.07 \pm 0.46$ arbitrary units; $p>0.05$ ).

\section{Discussion}

This study evaluated the influence of the antioxidant $N$-acetylcysteine on systemic oxidative stress and the intracellular signaling pathways MAPK and NF- $\kappa B$ in slow-twitch skeletal muscle of heart failure rats.

The MI rat has been a commonly used experimental model for inducing LV dysfunction and heart failure [28]. Ensuing heart failure develops slowly, as usually occurs in clinical settings. However, only rats with moderate to large MI develop HF [28]. In this study, groups MI-C and MI-NAC presented similar infarct sizes, approximately 48\%, which is considered large. Heart failure diagnosis was based on observation of clinical and pathologic features $[28,44]$. The higher right ventricle and lung weights in MI-C than Sham group confirmed heart failure diagnosis. $N$-acetylcysteine did not modify the frequency of heart failure features or right ventricle and lung weights.

Before $N$-acetylcysteine treatment, echocardiogram showed that MI-C and MI-NAC groups had a similar degree of cardiac injury (data not shown). At the end of experimental period, echocardiographic analysis showed that MI-C animals presented dilated left cardiac chambers with systolic and diastolic LV dysfunction compared to the Sham rats. Diastolic dysfunction in the MI-C group showed a restrictive pattern with an increased E/A ratio, which characterizes severe dysfunction [28]. Late treatment with NAC did not attenuate structural cardiac changes or systolic ventricular dysfunction. However, diastolic dysfunction was slightly improved as the E/A ratio was lower in MI-NAC than MI-C. Other authors have initiated NAC administration 24 hours [45] or two months [27] after inducing MI and observed attenuation of cardiac remodeling and improvement of systolic function. As in this study NAC was started four months after MI, it is probable that an advanced degree of cardiac injury was already established preventing a reverse remodeling process.

In our study, HF-induced skeletal myopathy was characterized by changes in metabolic enzymes activity and myosin heavy chain distribution in soleus muscle. Rats with heart failure presented decreased oxidative metabolism and more pronounced slow-twitch muscle fiber phenotype in soleus muscle. Furthermore, increased systemic oxidative stress was demonstrated by the higher malondialdehyde serum concentration in MI-C group compared to the Sham. In a previous work, we showed that increased oxidative stress also occurs in the soleus muscle of infarcted rats [14]. Oxidative stress has been related to changes in myofibrils and intrinsic myosin dysfunction during heart failure [46-48]. NAC administration did not change malondialdehyde levels, but reduced 3-nitrotyrosine concentration and oxidized glutathione compared to the MI-C group.

In this study, we showed for the first time that $N$-acetylcysteine administration modulates the MAPK and NF- $\kappa B$ intracellular signalling pathways in response to reactive oxygen species stimulus in slow-twitch skeletal muscle during HF.

Studies have shown that NF- $\kappa B$ and MAPK are critical pathways for muscle cell management of oxidative stress. In vitro, it is well stablished that oxidative stress activates both, MAPK and NF- $\kappa$ B pathways in C2 skeletal myoblasts, which resemble what happens in adult muscle satellite cells [49]. However, adult skeletal muscle response to increased ROS concentration may diverge from skeletal myoblast response, mainly due to differences in experimental model and interaction with other stimuli.

ERKs main function is related to anabolic processes such as cellular division, growth, and differentiation, while JNKs and p38-MAPK functions are associated to cellular responses to stress [15]. In C2 skeletal myoblasts, $\mathrm{H}_{2} \mathrm{O}_{2}$ induced strong ERK activation in a time- and KARGER 
dose-dependent profile [49]. In our study, however, we observed ERK1/2 activation was reduced in skeletal muscle and probable not related to ROS levels. On the other hand, ERK1/2 signaling has been associated with IGF-1-mediated hypertrophic effects in skeletal muscle [50]. Considering that IGF-1 and growth hormone are lower during HF [6, 51], inhibited ERK signaling was expected, as observed in this study. Simultaneous ERK and p38MAPK inhibition, associated with JNK activation in the infarcted rats may also have occurred due to dual specificity MAPK phosphatases (MKPs) activity, by still unclear mechanisms [52]. Shi et al. [53] demonstrated that ERK inhibition can be modulated in muscle cells by MAPK phosphatase MKP1. Another study demonstrated that ERK1/2 inhibition decreases fast fiber-specific gene and protein expression and induces the slow muscle fiber phenotype program in vitro and in vivo [54].

The role of p38 MAPK in myogenesis is related to both transcription and activation of muscle-specific transcription factors $[19,55]$. In our model, although p38 MAPK level was reduced in infarcted rats soleus muscle, MRF gene and protein expression was unchanged. NAC treatment only increased MRF4 gene expression, which was not combined with protein expression changes. The preserved MRF protein expression is coherent with both preserved mass and cross sectional fiber area in soleus muscle.

Previous studies have shown that Src is involved in MAPK activation, specifically JNK and ERK, stimulated by ROS [18]. Src activation also stimulates phosphorylation of JNK and Ser276 residue in NF- $\mathrm{KB}$ p65 subunit, in an ERK/MSK1 activation dependent way, and phosphorylation of Ser536 residue in NF- $\mathrm{B}$ p 65 subunit, independently of ERK activation [49]. In our study, Src and Ser536 residue phosphorylation levels in NF- $\kappa B$ p65 subunit were preserved in MI-C group and reduced in MI-NAC. However, JNK and p65-Ser276 residue phosphorylation behaviour was comparable to a chronic TNF- $\alpha$ activation response pattern. Jamaluddin et al. [43] showed that in cultured monocytes, acute TNF- $\alpha$ stimulation activates the three MAPK and MSK1. However, during chronic TNF- $\alpha$ stimulation, only JNK activation is sustained. Moreover, JNK activation was necessary for TNF- $\alpha$-induced ROS generation, and ROS acted as second messengers for JNK and NF- $\kappa$ B interaction [43]. Also, under TNF- $\alpha$ stimulation, antioxidant intervention did not attenuate JNK activation, but reduced p65Ser276 residue phosphorylation which is mediated by cAMP-dependent protein kinase A and not related to MSK1 [43]. In our study, NF- $\kappa B$ phosphorylation in different serine residues is at least in part related to oxidative stress as discussed above. However, we observed that increased IкB phosphorylation in infarcted rats was not modulated by NAC treatment, indicating augmented NF- $\mathrm{KB}$ activation, which is associated to increased circulating TNF- $\alpha$ [43].

\section{Conclusion}

We provide the first evidence that the antioxidant $N$-acetylcysteine can modulate MAPK and NF-KB signaling pathways in soleus muscle of rats with heart failure.

\section{Acknowledgments}

We are grateful to Jose Carlos Georgette and Victor Debbas for technical assistance and Colin Edward Knaggs for English editing. Financial support: Fundação de Amparo à Pesquisa do Estado de São Paulo (FAPESP, procs. 2012/21687-1, and 2012/07149-7), Conselho Nacional de Desenvolvimento Científico e Tecnológico (CNPq, procs. 306770/2015-6 and 308674/2015-4), and Pro-Reitoria de Pesquisa da Universidade Estadual Paulista (PROPe, UNESP).

\section{Disclosure Statement}

All authors declare that there is no conflict of interest to disclosure.

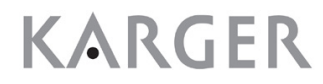




\section{Cellular Physiology Cell Physiol Biochem 2016;39:371-384

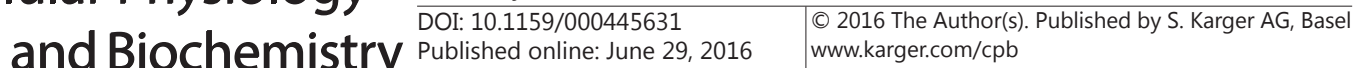

Martinez et al.: Oxidative Stress and Intracellular Signaling in Heart Failure-Induced

Myopathy

\section{References}

1 Harrington D, Anker SD, Chua TP, Webb-Peploe KM, Ponikowski PP, Poole-Wilson PA, Coats AJS:

Skeletal muscle function and its relation to exercise tolerance in chronic heart failure. J Am Coll Cardiol 1997;30:1758-1764.

2 von Haehling S: The wasting continuum in heart failure: from sarcopenia to cachexia. Proc Nutr Soc 2015;12:1-11.

3 Palus S, von Haehling S, Springer J: Muscle wasting: an overview of recent developments in basic research. J Cachexia Sarcopenia Muscle 2014;5:193-198.

4 Carvalho RF, Cicogna AC, Campos GER, Assis JMF, Padovani CR, Okoshi MP, Dal Pai-Silva M: Myosin heavy chain expression and atrophy in rat skeletal muscle during transition from cardiac hypertrophy to heart failure. Int J Exp Path 2003;84:201-206.

5 Carvalho RF, Dariolli R, Justulin Jr. LA, Sugizaki MM, Okoshi MP, Cicogna AC, Felisbino SL, Dal Pai-Silva M: Heart failure alters matrix metalloproteinase gene expression and activity in rat skeletal muscle. Int J Exp Pathol 2006;87:437-443.

6 Strassburg S, Springer J, Anker SD: Muscle wasting in cardiac cachexia. Intern J Biochem Cell Biol 2005;37:1938-1947.

7 Damatto RL, Martinez PF, Lima AR, Cezar MD, Campos DH, Oliveira SAJ, Guizoni DM, Bonomo C, Nakatani BT, Dal Pai Silva M, Carvalho RF, Okoshi K, Okoshi MP: Heart failure-induced skeletal myopathy in spontaneously hypertensive rats. Int J Cardiol 2013;167:698-703.

8 Lima AR, Martinez PF, Okoshi K, Guizoni DM, Zornoff LA, Campos DH, Oliveira SAJ, Bonomo C, Pai-Silva MD, Okoshi MP: Myostatin and follistatin expression in skeletal muscles of rats with chronic heart failure. Int J Exp Path 2010;91:54-62.

9 Lima AR, Martinez PF, Damatto RL, Cezar MD, Guizoni DM, Bonomo C, Oliveira SAJ, Dal-Pai Silva M, Zornoff LA, Okoshi K, Okoshi MP: Heart failure-induced diaphragm myopathy. Cell Physiol Biochem 2014;34:333345.

10 Middlekauff HR: Making the case for skeletal myopathy as the major limitation of exercise capacity in heart failure. Circ Heart Fail 2010;3:537-546.

11 Fulster S, Tacke M, Sandek A, Ebner N, Tschope C, Doehner W, Anker SD, von Haehling S: Muscle wasting in patients with chronic heart failure: Results from the studies investigating comorbidities aggravating heart failure (SICA-HF). Eur Heart J 2013;34:512-519.

12 Linke A, Adams V, Schulze PC, Erbs S, Gielen S, Fiehn E, Mobius-Winkler S, Schubert A, Schuler G, Hambrecht R: Antioxidative effects of exercise training in patients with chronic heart failure: increase in radical scavenger enzyme activity in skeletal muscle. Circulation 2005;111:1763-1770.

13 Tsutsui H, Ide T, Hayashidani S, Suematsu N, Shiomi T, Wen J, Nakamura K, Ichikawa K, Utsumi H, Takeshita A: Enhanced generation of reactive oxygen species in the limb skeletal muscles from a murine infarct model of heart failure. Circulation 2001;104:134-136.

14 Martinez PF, Bonomo C, Guizoni DM, Junior SA, Damatto RL, Cezar MD, Lima AR, Pagan LU, Seiva FR, Fernandes DC, Laurindo FRM, Novelli EL, Matsubara LS, Zornoff LA, Okoshi K, Okoshi MP: Influence of $\mathrm{N}$-acetylcysteine on oxidative stress in slow-twitch soleus muscle of heart failure rats. Cell Physiol Biochem 2015;35:148-159.

15 Kyriakis JM, Avruch J: Mammalian mitogen-activated protein kinase signal transduction pathways activated by stress and inflammation. Physiol Rev 2001;81:807-869.

16 Byun MS, Jeon KI, Choi JW, Shim JY, Jue DM: Dual effect of oxidative stress on NF- $\kappa B$ activation in HELA cells. Exp Mol Med 2002;34:332-339.

17 Bechara LR, Moreira JB, Jannig PR, Voltarelli VA, Dourado PM, Vasconcelos AR, Scavone C, Ramires PR, Brum PC: NADPH oxidase hyperactivity induces plantaris atrophy in heart failure rats. Int J Cardiol 2014;175:499-507.

18 Yoshizumi M, Abe J, Haendeler J, Huang Q, Berk BC: Src and Cas mediate JNK activation but not ERK1/2 and p38 kinases by reactive oxygen species. J Biol Chem 2000;275:11706-11712.

19 Chen S-E, Jin B, Li Y-P: TNF-alpha regulates myogenesis and muscle regeneration by activating p38 MAPK. Am J Physiol Cell Physiol 2007;292:C1660-C1671. 
Martinez et al.: Oxidative Stress and Intracellular Signaling in Heart Failure-Induced Myopathy

20 Strle K, Broussard SR, McCusker RH, Shen W-H, LeCleir JM, Johnson RW, Freund GG, Dantzer R, Kelley KW: C-jun N-terminal kinase mediates tumor necrosis factor-alpha suppression of differentiation in myoblasts. Endocrinology 2006;147:4363-4373.

21 Karin M, Ben-Neriah Y: Phosphorylation meets ubiquitination: the control of NF-кB activity. Annu Rev Immunol 2000;18:621-663.

22 Vermeulen L, De Wilde G, Van Damme P, Vanden Berghe W, Haegeman G: Transcriptional activation of the NF-kappaB p65 subunit by mitogen- and stress-activated protein kinase-1 (MSK1). EMBO J 2003;22:13131324.

23 Bohuslav J, Chen LF, Kwon H, Mu Y, Greene WC: P53 induces NF-kappaB activation by an IkappaB kinase-independent mechanism involving phosphorylation of p65 by ribosomal S6 kinase 1. J Biol Chem 2004;279:26115-26125.

24 Ponnappan S, Uken-Trebilcock G, Lindquist M, Ponnappan U: Tyrosine phosphorylation-dependent activation of NF-кB is compromised in T cells from the elderly. Exp Gerontol 2004;39:559-566.

25 Munzel T, Gori T, Keaney Jr JF, Maack C, Daiber A: Pathophysiological role of oxidative stress in systolic and diastolic heart failure and its therapeutic implications. Eur Heart J 2015;36:2555-2564.

26 Fratelli M, Goodwin LO, Orom UA, Lombardi S, Tonelli R, Mengozzi Mea: Gene expression profiling reveals a signaling role of glutathione in redox regulation. Proc Natl Acad Sci USA 2005;102:13998-14003.

27 Adamy C, Mulder P, Khouzami L, Andrieu-Abadie N, Defer N, Candiani G, Pavoine C, Caramelle P, Souktani R, Le Corvoisier P, Perier M, Kirsch M, Damy T, Berdeaux A, Levade T, Thuillez C, Hittinger L, Pecker F: Neutral sphingomyelinase inhibition participates to the benefits of $\mathrm{N}$-acetylcysteine treatment in post-myocardial infarction failing heart rats. J Mol Cell Cardiol 2007;43:344-353.

28 Martinez PF, Okoshi K, Zornoff LA, Oliveira SAJ, Campos DH, Lima AR, Damatto RL, Cezar MD, Bonomo C, Guizoni DM, Padovani CR, Cicogna AC, Okoshi MP: Echocardiographic detection of congestive heart failure in postinfarction rats. J Appl Physiol 2011;111:543-551.

29 Gomes MJ, Martinez PF, Campos DH, Pagan LU, Bonomo C, Lima AR, Damatto RL, Cezar MD, Damatto FC, Rosa CM, Garcia CM, Reyes DR, Fernandes AA, Fernandes DC, Laurindo FR, Okoshi K, Okoshi MP: Beneficial effects of physical exercise on functional capacity and skeletal muscle oxidative stress in rats with aortic stenosis-induced heart failure. Oxid Med Cell Longev 2016;2016:8695716.

30 Pagan LU, Damatto RL, Cezar MD, Lima AR, Bonomo C, Campos DH, Gomes MJ, Martinez PF, Oliveira SA Jr, Gimenes R, Rosa CM, Guizoni DM, Moukbel YC, Cicogna AC, Okoshi MP, Okoshi K: Long-term low intensity physical exercise attenuates heart failure development in aging spontaneously hypertensive rats. Cell Physiol Biochem 2015;36:61-74.

31 Cezar MD, Damatto RL, Pagan LU, Lima AR, Martinez PF, Bonomo C, Rosa CM, Campos DH, Cicogna AC, Gomes MJ, Oliveira SA Jr, Blotta DA, Okoshi MP, Okoshi K: Early spironolactone treatment attenuates heart failure development by improving myocardial function and reducing fibrosis in spontaneously hypertensive rats. Cell Physiol Biochem 2015;36:1453-1466.

32 Oliveira Junior SA, Dal Pai-Silva M, Martinez PF, Lima-Leopoldo AP, Campos DH, Leopoldo AS, Okoshi MP, Okoshi K, Padovani CR, Cicogna AC: Diet-induced obesity causes metabolic, endocrine and cardiac alterations in spontaneously hypertensive rats. Med Sci Monit 2010;16:BR367-BR373.

33 Okoshi K, Ribeiro HB, Okoshi MP, Matsubara BB, Gonçalves G, Barros R, Cicogna AC: Improved systolic ventricular function with normal myocardial mechanics in compensated cardiac hypertrophy. Jpn Heart J 2004;45:647-656.

34 Okoshi K, Fioretto JR, Okoshi MP, Cicogna AC, Aragon FF, Matsubara LS, Matsubara BB: Food restriction induces in vivo ventricular dysfunction in spontaneously hypertensive rats without impairment of in vitro myocardial contractility. Braz J Med Biol Res 2004;37:607-613.

35 Lang RM, Bierig M, Devereux RB, Flachskampf FA, Foster E, Pellikka PA, Picard MH, Roman MJ, Seward J, Shanewise JS, Solomon SD, Spencer KT, Sutton MSJ, Stewart WJ: Recommendations for chamber quantification: a report from the American Society of Echocardiography's Guidelines and Standards Committee and the Chamber Quantification Writing Group, developed in conjunction with the European Association of Echocardiography, a branch of the European Society of Cardiology. J Am Soc Echocardiogr 2005;18:1440-1463.

36 Martinez PF, Okoshi K, Zornoff LA, Carvalho RF, Oliveira Junior SA, Lima AR, Campos DH, Damatto RL, Nogueira CR, Dal Pai-Silva M, Okoshi MP: Chronic heart failure-induced skeletal muscle atrophy, necrosis, and myogenic regulatory factors changes. Med Sci Monit 2010;16:374-383. 
Martinez et al.: Oxidative Stress and Intracellular Signaling in Heart Failure-Induced Myopathy

37 Burneiko RC, Diniz YS, Galhardi CM, Rodrigues HG, Ebaid GM, Faine LA, Padovani CR, Cicogna AC, Novelli EL: Interaction of hypercaloric diet and physical exercise on lipid profile, oxidative stress and antioxidant defenses. Food Chem Toxicol 2006;44:1167-1172.

38 Li L, Chen C-YO, Aldini G, Johnson EJ, Rasmussen H, Yoshida Y, Niki E, Blumberg JB, Russell RM, Yeum $\mathrm{K}-\mathrm{J}$ : Supplementation with lutein or lutein plus green tea extracts does not change oxidative stress in adequately nourished older adults. J Nutr Biochem 2010;21:544-549.

39 Cezar MD, Damatto RL, Martinez PF, Lima AR, Campos DH, Rosa CM, Guizoni DM, Bonomo C, Cicogna AC, Gimenes R, Pagan LU, Okoshi MP, Okoshi K: Aldosterone blockade reduces mortality without changing cardiac remodeling in spontaneously hypertensive rats. Cell Physiol Biochem 2013;32:1275-1287.

40 Rosa CM, Xavier NP, Campos DH, Fernandes AA, Cezar MD, Martinez PF, Cicogna AC, Gimenes C, Gimenes R, Okoshi MP, Okoshi K: Diabetes mellitus activated fetal gene program and intensifies cardiac remodeling and oxidative stress in aged spontaneously hypertensive rats. Cardiovasc Diabetol 2013;12:152.

41 Oliveira-Junior SA, Martinez PF, Guizoni DM, Campos DH, Fernandes T, Oliveira EM, Okoshi MP, Okoshi K, Padovani CR, Cicogna AC: AT1 receptor blockade attenuates insulin resistance and myocardial remodeling in rats with diet-induced obesity. PLoS One 2014;9:e86447.

42 Yan X, Schuldt AJ, Price RL, Amende I, Liu FF, Okoshi K, Ho KK, Pope AJ, Borg TK, Lorell BH, Morgan JP: Pressure overload-induced hypertrophy in transgenic mice selectively overexpressing AT2 receptors in ventricular myocytes. Am J Physiol Heart Circ Physiol 2008;294:1274-1281.

43 Jamaluddin M, Wang S, Boldogh I, Tian B, Brasier AR: TNF-alpha-induced NF-кB/RelA Ser276 phosphorylation and enhanceosome formation is mediated by an ROS-dependente PKAc pathway. Cell Signal 2007;19:1419-1433.

44 Cicogna AC, Robinson KG, Conrad CH, Singh K, Squire R, Okoshi MP, Bing OHL: Direct effects of colchicine on myocardial function. Studies in hypertrophied and failing spontaneously hypertensive rats. Hypertension 1999;33:60-65.

45 Lee TM, Lai PY, Chang NC: Effect of N-acetylcysteine on sympathetic hyperinnervation in post-infarcted rat hearts. Cardiovasc Res 2010;85:137-146.

46 Coirault C, Guellich A, Barbry T, Samuel JL, Riou B, Lecarpentier Y: Oxidative stress of myosin contributes to skeletal muscle dysfunction in rats with chronic heart failure. Am J Physiol Heart Circ Physiol 2007;292:H1009-H1017.

47 Bowen TS, Mangner N, Werner S, Glaser S, Kullnick Y, Schrepper A, Doenst T, Oberbach A, Linke A, Steil L, Schuler G, Adams V: Diaphragm muscle weakness in mice is early-onset post-myocardial infarction and associated with elevated protein oxidation. J Appl Physiol 2015;118:11-19.

48 Ahn B, Beharry AW, Frye GS, Judge AR, Ferreira LF: NAD(P)H oxidase subunit p47phox is elevated, and p47phox knockout prevents diaphragm contractile dysfunction in heart failure. Am J Physiol Lung Cell Mol Physiol 2015;309:L497-L505.

49 Kefaloyianni E, Gaitanaki C, Beis I: ERK1/2 and p38-MAPK signalling pathways, through MSK1, are involved in NF-kB transactivation during oxidative stress in skeletal myoblasts. Cell Signal 2006;18:22382251.

50 Haddad F, Adams GR: Inhibition of MAP/ERK kinase prevents IGF-1 induced hypertrophy in rat muscles. J Appl Physiol 2004;96:203-210.

51 Toth MJ, Ades PA, LeWinter MM, Tracy RP, Tchernof A: Skeletal muscle myofibrillar mRNA expression in heart failure: relationship to local and circulating hormones. J Appl Physiol 2006;100:35-41.

52 Chu Y, Solski PA, Khosvavi-Far R, Der CJ, Kelly K: The mitogen-activated protein kinase phosphatases PAC1, MKP-1, and MKP-2 have unique substrate specificities and reduced activity in vivo toward the ERK2 sevenmaker mutation. J Biol Chem 1996;271:6497-6501.

53 Shi H, Scheffler JM, Zeng C, Pleitner JM, Hannon KM, Grant AL: Mitogen-activated protein kinase signaling is necessary for the maintenance of skeletal muscle mass. Am J Physiol Cell Physiol 2009;296:C1040-C1048.

54 Shi H, Scheffler JM, Pleitner JM, Zeng L, Park S, Hannon KM, Grant AL, Gerrard DE: Modulation of skeletal muscle fiber type by mitogen activated protein kinase signaling. FASEB J 2008;22:2990-3000.

55 Suelves M, Lluis F, Ruiz V, Nebreda AR, Munoz-Canoves P: Phosphorylation of MRF4 transactivation domain by p38 mediates repression of specific mygenic genes. EMBO J 2004;23:365-375. 